\title{
EPIDEMIOLOGY OF PSYCHIATRIC DISORDERS IN DELIBERATE SELF HARM VICTIMS
}

Kiran Kumar P. K, Sukesh, Anil Kakunje, Prashantha Bhagavath

1. Associate Professor, Department of Psychiatry, A. J. Institute of Medical Sciences, Mangalore, India.

2. Associate Professor, Department of Pathology, Srinivas Institute of Medical Sciences and Research Centre, Mangalore, India.

3. Associate Professor, Department of Psychiatry, Yenepoya Medical College, Mangalore, India.

4. Associate Professor, Department of Forensic Medicine \& Toxicology, Kasturba Medical College, Manipal: 576104,

\section{CORRESPONDING AUTHOR}

Dr. Prashantha Bhagavath,

Associate Professor of Forensic Medicine \& Toxicology,

Kasturba Medical College,

Manipal: 576104, India.

E-mail: dr_fmpb@yahoo.com

Ph: 00919448624014.

ABSTRACT: There is limited literature linking psychiatric disorders to deliberate self from India. The study will certainly add to the existing information worldwide and will help us to develop preventive modalities in deliberate self harm and its recurrence. This prospective study extended for a period of one year from January 2010 to December 2010 on deliberate self harm victims aged 20 years and above who reported to the one of the tertiary health care center and teaching hospital of southern Karnataka; and referred patients to the psychiatric consultation to study the epidemiology of psychiatric disorders in deliberate self-harm (DSH) victims. The research was conducted on total of 113 of deliberate self harm victims. $69.03 \%$ of deliberate self harm victims were males. $80.53 \%$ of victims are in the age group of 20 to 39 years. $43.36 \%$ deliberate self harm victims were employed. $77.88 \%$ deliberate self harm victims committed the act inside their residence. Poisoning was the commonest $(76.11 \%)$ method of self-harm. Psychiatric illness was seen in $71.68 \%$ deliberate self harm victims and depression was the major culprit among them. This study emphasizes the role of psychiatric disorders in deliberate self harm which will go a long way in its prevention and recurrence.

KEYWORDS: Deliberate self harm; Psychiatric disorders; Poisoning; Depression

INTRODUCTION: Deliberate self harm (DSH) is an "an act with non-fatal outcome in which an individual deliberately initiates a non-habitual behaviour, that without intervention from others will cause self-harm, or deliberately ingests a substance in excess of the prescribed or generally recognised dosage, and which is aimed at realising changes that the person desires via the actual or expected physical consequences" ${ }^{1,2}$ There are increasing instances of deliberate selfharm (DSH) episodes worldwide and is a challenging health issue. Deliberate self-harm is an complex event, associated with psychosomatic, biological, social factors and one important factor being psychiatric disorder.,4 Current literature on DSH from countries worldwide have reported rising rates of psychiatric disorder. ${ }^{5-9}$ Comorbidity of psychiatric disorder was common in various studies.7,8,11 The objective of the present study was to study the psychiatric morbidity DSH victims in Mangalore, a coastal district in the Karnataka, India. 
MATERIALS AND METHODS: The present prospective study extended for a period of one year from January 2010 to December 2010. The subjects were deliberate self harm victims, aged 20 years and above who presented to the one of the tertiary health care center and teaching hospital of southern Karnataka; and referred patients to the psychiatric consultation. As per the definition of DSH included acts of self-poisoning and self-injury.11 Victims under the age of 20 years, ambiguous history regarding the event or who are incapable to understand or otherwise participate in the study (e.g. medically in poor condition, organic brain syndrome, severe mental disturbance, severe learning deficits) were excluded from the study. In case the patient was discharged before collecting all the information the remaining information was obtained during the follow up period. Information pertaining to the cases included in the present research was also gathered from the accompanying person with the victim. Informed consent was taken from all the patients who were included in the study. The study included 113 cases of deliberate self harm and data regarding socio-demographic profile and their psychiatric evaluation were collected in the pre-structured proforma. Data were entered and analyzed using the Statistical Package for the Social Sciences (SPSS, 2003)

RESULTS: Total of one hundred thirteen victims with deliberate self harm reported to the tertiary health care center and teaching hospital of southern Karnataka and victims who were referred for psychiatric consultation during the period of one years (January 2010 to December 2010. Of the 113 patients included in the study, 78 (69.03\%) were males and 35 (30.97\%) were females as depicted in the Table 1.

Majority of deliberate self harm cases were in the age group of 20 to 29years, followed by the age group of 30 to 39 years, and 50 to 59 years respectively, as depicted in the Table 2 . Most of the victims belonged to the Hindu religion (77.88\%) followed by Christians $(11.50 \%)$ and Muslims (10.62\%). DSH was accomplished inside their dwellings in most of the cases $(77.88 \%)$.

DISCUSSION: Deliberate self-harm is an acute, non-fatal act of self-harm carried out deliberately in the form of an acute episode of behavior by an individual with variable motivation. ${ }^{1,12}$ Other terms used to explain deliberate are parasuicide and attempted suicide. Prevalent ways of achieving deliberate self-harm includes self-cutting, self-poisoning, for example by overdosing on medicines. Deliberate self-harm encompass high suicidal intent, meticulous planning, and brutal outcome of the method used. Other acts of deliberate self-harm are characterised by no or low intention of suicide, lack of planning and concealing of the act, and low lethality of the method used. Suicide differs from deliberate self harm wherein suicide is an act with a fatal outcome, deliberately initiated and performed by the person with the knowledge or expectation of its fatal outcome.13 Deliberate self-harm may encountered in variety of conditions which include substance abuse, eating disorders, post-traumatic stress disorder, major depression, anxiety disorders, personality disorders and schizophrenia. ${ }^{14-19}$

The present study showed male preponderance. The studies conducted globally demonstrate a varying trend. Some researchers propose that deliberate self harm has female predilection ${ }^{16-29}$, whereas others proposes view contrary to this. ${ }^{30-32}$ Several other studies found self-harm to be gender neutral.19,33-36 Most of the deliberate self harm victims fall in the age group of 20 to 39 years. The similar trend observed in the studies conducted in northern India. ${ }^{37}$ The lower rates of deliberate self harm in lower age group can be explained with several reasons. Children do not develop definite ideas of the nature and thoughts of death before the 
age of 7 or 8 years and do not get a more reliable insight in the phenomenon before the age of 12 or 14 years. Their immature mind do not process the ability to plan and execute the act of deliberate self harm 38 In comparison with adolescents, children are better secluded against contemplating and planning suicide by the lower incidence of depressive disorders, the higher extent of family care and the cordial relationship with the parents. The victims less than 15 years of age rarely suffer from psychiatric disorders, expressed less suicidal intent and were less exposed to stressors like interpersonal/parental conflicts or romantic disappointment. The conclusion was drawn that children are not more resilient but are less exposed to risk factors and for that reason have a lower suicide rate. ${ }^{39}$

Our study is in concurrence with earlier studies which revealed that deliberate self harm are generally executed when the patient is at his familiar place i.e. at his residence. ${ }^{40-42}$ Deliberate self harm was usually committed in locality familiar to the victim, in particular the parental flat or the close vicinity of their home. In keeping with the reflections concerning the choice of the method, the familiar setting is possibly preferred because it provides easy access to the necessary implements and makes possible the commitment of suicide within a short time leaving no opportunity to reconsider the decision. ${ }^{41}$ Our study showed preponderance of employed individuals resorting to this drastic step. This may be explained from the fact that employed individuals are surrounded by stress at work place, from the family and their inability cope up with professional and personal life. Another study revealed that as many as $35 \%$ of college students report having performed at least one self-harm behavior in their lifetime.43 Several studies have found higher rates of self-harm in individuals from younger generations. $16,33,34,44$

Self poisoning was the commonest method of deliberate self-harm in our study. The methods of deliberate self harm employed generally reflect the different possibilities available in the community. Study conducted by Birkhead et al. revealed drugs or poisons to be most common methods of attempted suicide (71.1\%), and the use of firearms was the most common method of suicide (69.8\%). ${ }^{45,46}$ Some researchers reported a substantially rise of self-inflicted gunshot wounds. ${ }^{41,47}$ Usage of firearm, sharp edged weapons for accomplishing deliberate self harm are not found in our study. Our study emphasized the role of psychiatric morbidity in deliberate self harm. The psychiatric disorders encountered in our study in the descending order of its existence were depression, bipolar disorders, schizophrenia and borderline personality disorder. The role of psychiatric disorders in deliberate self harm has been reported by various researchers both at national and international level. ${ }^{10,48}$, There is extensive literature attributing the role of depression and personality disorders in deliberate self harm. $6-8,10,48$ This study emphasizes the role of psychiatric disorders in deliberate self harm which will go a long way in its prevention and recurrence.

\section{REFERENCES:}

1. Hawton K, Fagg J, Simkin S, Bale E, Bond A. Trends in deliberate self-harm in Oxford, 1985-1995. Implications for clinical services and the prevention of suicide. British Journal of Psychiatry 1997;171:556 -560.

2. Kapur, N., House, A., Creed, F, et al. Management of deliberate self-poisoning in adults in four teaching hospitals: descriptive study. British Medical Journal 1998;316:831-832.

3. Newson-Smith J, Hirsch S. Psychiatric symptoms in self-poisoning patients. Psychological Medicine 1979;9:493-500. 
4. Urwin P, Gibbons J. Psychiatric diagnosis in self-poisoning patients. Psychological Medicine 1979; 9:501-507.

5. Barraclough B, Bunch J, Nelson B, et al. A hundred cases of suicide: clinical aspects. British Journal of Psychiatry 1974;125:355-373.

6. Ennis J, Barnes RA, Kennedy S, et al. Depression in self-harm patients. British Journal of Psychiatry 1989;154:41-47.

7. Suominen $\mathrm{K}$, Isometsa $\mathrm{E}$, Henriksson $\mathrm{M}$, et al. Consultation versus research diagnoses of mental disorders among suicide attempters. Nordic Journal of Psychiatry 1999;53:253256.

8. Ferreira de Castro E, Cunha M, Pimenta F, et al. Parasuicide and mental disorders. Acta Psychiatrica Scandinavica 1998; 97:25 -31.

9. Foster T, Gillespie K, McClelland R. Mental disorders and suicide in Northern Ireland. British Journal of Psychiatry 1997;170:447-452.

10. Beautrais A, Joyce P, Mulder R, et al. Prevalence and comorbidity of mental disorders in persons making serious suicide attempts: a case control study. American Journal of Psychiatry 1996;153:1009-1014.

11. Platt S, Bille-Brahe U, Kerkhof A, et al. Parasuicide in Europe: the WHO/EURO multicentre study on parasuicide. I. Introduction and preliminary analysis for 1989. Acta Psychiatrica Scandinavica 1992;85:97-104.

12. Pattison EM, Kahan J. The deliberate self-harm syndrome. Am J Psychiatry 1983; 140:867-872.

13. Herpertz S. Self-injurious behavior: psychopathological and nosological characteristics in subtypes of self-injurers. Acta Psychiatr Scand 1995; 91:57-68.

14. van der Kolk BA, Perry JC, Herman JL. Childhood origins of self-destructive behavior. Am J Psychiatry 1991; 148:1665-1671.

15. Haw C, Hawton K, Houston K, Townsend E. Psychiatric and personality disorders in deliberate self-harm patients. Br J Psychiatry 2001;178:48-54.

16. Zlotnick C, Mattia JI, Zimmerman M. Clinical correlates of self-mutilation in a sample of general psychiatric patients. J Nerv Ment Dis 1999; 187:296-301.

17. Herpertz S, Sass H, Favazza A. Impulsivity in self-mutilative behavior: psychometric and biological findings. J Psychiatr Res 1997; 31:451-465.

18. Simeon D, Stanley B, Frances A, Mann JJ, Winchel R, Stanley M. Self-mutilation in personality disorders: psychological and biological correlates. Am J Psychiatry 1992; 149:221-226.

19. Stanley B, Gameroff MJ, Michalsen V, Mann JJ. Are suicide attempters who self-mutilate a unique population? Am J Psychiatry 2001; 158:427-432.

20. Ogundipe LO: Suicide attempts vs deliberate self-harm (letter). Br J Psychiatry 1999; 175:90.

21. Suyemoto KL. The functions of self-mutilation. Clin Psychol Rev 1998; 18:531-554.

22. Chowdhury AN, Sanyal D, Dutta SK, Weiss MG. Deliberate self harm by ingestion of poisons on Sagar Island in Sundarban delta,India. Int Med J 2003;10:85-91.

23. Srivastava MK, Sahoo RN, Ghotekar LH, Dutta S, Danabalan M,Dutta TK, et al. Risk factors associated with attempted suicide: A case-control study. Indian J Psychiatry 2004;46:33-8.

24. Sharma RC. Attempted suicide in Himachal Pradesh. Indian J Psychiatry 1998;40: 50-4. 
25. Minnaar GK, Schlebusch L, Levin A. A current study of parasuicidein Durban. S Afr Med J 1980;57(6):204-7.

26. Goldney RD, Harris LC, Badri A, Michael S, Fisher L. Suicidal ideation in Sudanese women. Crisis 1998;19(4):154-8.

27. Alem A, Kebede D, Jacobsson L, Kullgren G. Suicide attempts among adults in Butajira. Ethiopia Act Psychiat Scand Suppl 1999;397:70-6.

28. Mzezewa S, Jonsson K, Aberg M, Salemark L. A prospective study of suicidal burns admitted to the Harare burns unit. Burns 2000;26(5):460-4.

29. Ndosi NK, Mbonde MP, Lyamuya E. Profile of suicide in Dares Salaam. East Afr Med J 2004;81(4):207-11.

30. Kumar SPN. Age and gender related analysis of psychosocial factors in attempted suicide. Indian J Psychiatry 1998;40:338-45.

31. Ponnudurai R, Jeykar J, Saraswathy M. Attempted suicides in Madras. Indian J Psychiatry 1986;28:59-62.

32. Sathyavathi K. Attempted suicide in psychiatric patients. Indian J Psychiatry 1971;13:37-48.

33. Briere J, Gil E. Self-mutilation in clinical and general population samples: prevalence, correlates, and functions. Am J Orthopsychiatry 1998; 68:609-620.

34. Soloff PH, Lis JA, Kelly T, Cornelius J, Ulrich R. Self-mutilation and suicidal behavior in borderline personality disorder. J Personal Disord 1994; 8:257-267.

35. Nijman HLI, Dautzenberg M, Merckelbach HLGJ, Jung P, Wessel I, Campo J. Selfmutilating behavior in psychiatric inpatients. Eur Psychiatry 1999; 14:4-10.

36. Gratz KL. Measurement of deliberate self-harm: preliminary data on the Deliberate SelfHarm Inventory. J Psychopathology and Behavioral Assessment 2001; 23:253-263.

37. Midha P. A comprehensive study of deliberate self harm, a dissertation submitted to university of Rajasthan for MD psychiatry 2001.

38. Eggers G, Lempp R, Nissen G, Strunk P. Kinder-und Jugendpsychiatrie. Berlin: Springer; 1993.

39. Groholt B, Ekeberg O, Wichstrom L, Haldorsen T. Suicide among children and younger and older adolescents in Norway: a comparative study. J Am Acad Child Adolesc Psychiatr 1998; 37:473-481.

40. Hoberman HM, Garfinkel BD. Completed suicide in children and adolescents. J Am Acad Child Adolesc Psychiatr 1988; 27:689-695.

41. Lee CJ, Collins KA, Burgess SE. Suicide under the age of eighteen: A 10-year retrospective study. Am J Forensic Med Pathol 1999; 20: 27-30.

42. Lecomte D, Fornes P. Suicide among youth and young adults, 15 through 24 years of age. A report of 392 cases from Paris,1989-1996. J Forensic Sci 1998; 43: 964-968.

43. Gratz KL. Measurement of deliberate self-harm: preliminary data on the Deliberate SelfHarm Inventory. J Psychopathology and Behavioral Assessment 2001; 23:253-263.

44. Shearer SL. Phenomenology of self-injury among inpatient women with borderline personality disorder. J Nerv Ment Dis 1997; 182:524-526.

45. Birkhead GS, Galvin VG, Meehan PJ, O'Carroll PW, Mercy JA. The emergency department in surveillance of attempted suicide: findings and methodologic considerations. Public Health Reports 1993; 108: 323-31

46. Odejide AO, Williams AO, Ohaeri JU, Ikuesan BA. The epidemiology of deliberate selfharm. The Ibadan experience. B J Psych 1986; 149: 734. 
47. Narang BL, Mishra BP, Mohan N. Attempted suicide in Ludhiana.Indian J Psychiatry 2000;42:83-7.

48. Gupta B, Trzepacz P. Serious overdosers admitted to a general hospital: comparison with nonoverdose self-injuries and medically ill patients with suicidal ideation. General hospital psychiatry 1997; 19:209-215.

Table 1: Gender distribution of DSH victims $(n=113)$

\begin{tabular}{|l|l|l|}
\hline \multicolumn{1}{|c|}{ Sex } & \multicolumn{1}{|c|}{ Number of cases } & Percentage \% \\
\hline Male & 78 & 69.03 \\
\hline Female & 35 & 30.97 \\
\hline
\end{tabular}

Table 2: Age-wise distribution of DSH victims $(n=113)$

\begin{tabular}{|l|l|l|}
\hline \multicolumn{1}{|c|}{ Age in years } & \multicolumn{1}{c|}{ Number of cases } & \multicolumn{1}{r|}{ Percentage } \\
\hline $20-29$ & 55 & 48.67 \\
\hline $30-39$ & 36 & 31.86 \\
\hline $40-49$ & 5 & 4.42 \\
\hline $50-59$ & 13 & 11.51 \\
\hline $60-69$ & 2 & 1.77 \\
\hline$>70$ & 2 & 1.77 \\
\hline
\end{tabular}

Most of the victims (43.36\%) who suffered deliberate self ham were employed as depicted in the Table 4.

Table 3: Employment status of DSH victims $(n=113)$

\begin{tabular}{|l|l|l|}
\hline \multicolumn{1}{|c|}{ Employment status } & \multicolumn{1}{c|}{ Number of cases } & \multicolumn{1}{c|}{ Percentage } \\
\hline Employed & 49 & 43.36 \\
\hline Unemployed & 28 & 24.78 \\
\hline Household & 26 & 23.01 \\
\hline Student & 8 & 7.08 \\
\hline Not known & 2 & 1.77 \\
\hline
\end{tabular}

Most of the victims consumed poisons (76.11\%) followed by self injury as depicted in the Table 4. 
Table 4: Method employed by DSH victims (n=113)

\begin{tabular}{|l|l|l|}
\hline Method & Number of cases & Percentage \\
\hline Self poisoning & 86 & 76.11 \\
\hline Self injury & 25 & 22.12 \\
\hline Both & 2 & 1.77 \\
\hline
\end{tabular}

Psychiatric illness was said to be the reason for deliberate self harm in $71.68 \%$ of victims as illustrated in the Table 5.

Table 5: Method employed by DSH victims $(n=113)$

\begin{tabular}{|l|l|l|}
\hline \multicolumn{1}{|c|}{ Method } & \multicolumn{1}{|c|}{ Number of cases } & \multicolumn{1}{c|}{ Percentage } \\
\hline Psychiatric illness & 81 & 71.68 \\
\hline Financial problem & 16 & 14.16 \\
\hline Love failure & 8 & 7.08 \\
\hline Failure in the exam & 4 & 3.54 \\
\hline $\begin{array}{c}\text { To threaten the family } \\
\text { members }\end{array}$ & \multicolumn{1}{|c|}{4} & 3.54 \\
\hline
\end{tabular}

Among the psychiatric disorders most of the victims were suffering from depression followed by bipolar disorders, schizophrenia and borderline personality disorder as illustrated in Table 6.

Table 6: Type of psychiatric illness in DSH victims $(n=81)$

\begin{tabular}{|l|l|l|}
\hline \multicolumn{1}{|c|}{ Type of psychiatric illness } & \multicolumn{1}{c|}{ Number of cases } & \multicolumn{1}{c|}{ Percentage } \\
\hline Depression & 66 & 81.48 \\
\hline Bipolar disorders & 11 & 13.58 \\
\hline Schizophrenia & 3 & 3.70 \\
\hline Borderline personality disorder & 1 & 1.24 \\
\hline
\end{tabular}

